\title{
Satisfaction with life, depression, anxiety, and stress among adolescent girls in Tehran: a cross sectional study
}

\author{
Sara-Sadat Hoseini-Esfidarjani ${ }^{1}$ (D), Kiarash Tanha ${ }^{2}$ (D) and Reza Negarandeh ${ }^{3^{*}}$ (10)
}

\begin{abstract}
Objective and background: Mental health is a widespread field that entails variables such as the presence of positive feelings like satisfaction with life and lack of negative emotions like depression, anxiety, and stress. This research aimed to study the prevalence of depression, anxiety, stress, and satisfaction with life as dimensions of adolescent girls' mental health in Tehran.

Methodology: The population considered in this cross-sectional study consisted of adolescent girls in the last grade of high school in Tehran. Research samples were selected using multi-stage sampling. The sample size in this study was 491 and the research tools used were standardized questionnaires. Descriptive and inferential statistics included Spearman, ANOVA, and regression tests were used.

Findings: More than half of the adolescents experienced common symptoms of depression, anxiety, and stress. About 30\% of adolescents were dissatisfied with life to some extent. Satisfaction with life was negatively correlated with age, depression, anxiety, and stress. Age and depression were predictor variables of life satisfaction based on the regression model.

Conclusion: A considerable percentage of adolescents suffered some form of depression, anxiety, and stress symptoms and were notably dissatisfied with life. Regarding the importance of satisfaction with life in having a joyful life and its role in initiating depression, anxiety, and stress, our findings highlight the need for interventions to prevent depression, anxiety, and stress and enhance life satisfaction among adolescents.
\end{abstract}

Keywords: Satisfaction with life, Depression, Anxiety, Stress, Adolescent girls

\section{Introduction}

According to the World Health Organization (WHO) definition, "mental health is defined as a state of wellbeing in which every individual realizes his or her potential, can cope with the normal stresses of life, can work productively and fruitfully, and is able to make a contribution to his or her community" [1]. Since mental wellbeing is measured using variables such as; satisfaction

\footnotetext{
*Correspondence: rnegarandeh@tums.ac.ir

${ }^{3}$ Nursing and Midwifery Care Research Center, Tehran University of Medical Sciences, Nosrat St., Tohid Sq., Tehran 1419733171, Iran Full list of author information is available at the end of the article
}

with life, anxiety, depression, stress, and disappointment, it can be said that these variables are dimensions of mental-health and well-being [2].

Adolescence (10-19years old) is the period of transition from childhood to adulthood [3] and it is also a critical step that involves the promotion and preservation of important emotional habits that foster mental well-being [4]. Poor mental health can have significant effects on the health and development of adolescents and is associated with various adverse social consequences (that is, alcohol and drug abuse, delinquent behavior, school dropout) [5]. 
Satisfaction with life is a positive dimension of wellbeing, which refers to a comparative process in which people assess their quality of life based on their own standards [6]. Regarding satisfaction with life, Moksnes and Espnes showed that the mean score of satisfaction with life among Norwegian girls was $22.31 \pm 6.01$, and based on the satisfaction with life scale used in this study; girls were a little satisfied [7]. In the study by $\mathrm{Al}$ Khatib (2013), the mean score of satisfaction with life among the United Arab Emirates (UAE) students was higher than the neutral level [8]. Moreover, satisfaction with life in adolescents predicts the most salient social (relationship with parents), behavioral (delinquency) [9], and psychological dimensions (depression and anxiety) [10].

In the early years of childhood, diagnosed mental health disorders are higher in boys than girls. However, depressive disorders and anxiety are often more deleterious to girls by adolescence due to inequalities. Because there is usually no intervention during adolescence, these disorders can persist into adulthood and have debilitating long-term consequences for mental health [11]. Young women are also vulnerable to several factors, including poverty-related hardship, physical abuse, less access to education and employment opportunities, and limited mobility [12].

Negative feelings like depression, anxiety, and stress are among the most common mental health problems [13]. According to the American Psychiatric Association and the DMS-5, "Depression is a common and serious medical illness that negatively affects how you feel, the way you think and how you act" [14]. Depression has been known as the first mental health priority among adolescents due to its high prevalence, recurrence, and ability to cause significant impairment [15].. On the other hand, stress is a challenge or threat to well-being. It is a process in which environmental demands exceed an organism's adaptation capacity, lead to mental and biological changes, and expose people to risks. Stress is an essential part of life because its persistence may lead to various psychological problems such as involvement in high-risk behaviors [16]. In comparison, anxiety is a natural reaction to stress. It can be a beneficial implication that often alerts us in dangerous situations, thereby increasing our readiness to act promptly. Nevertheless, anxiety disorders are different from feelings of nervousness or anxiousness and entail extreme fear or anxiety [17]. According to the WHO report, $10-20 \%$ of adolescents throughout the world experience mental health disorders [4]. To date, within published literature, various studies have reported a notable proportion of adolescents experiencing one or more mental disorders. For instance: a systematic review by Polanczyket et al. (2015) showed that the prevalence of mental disorders in children and adolescents in 27 countries was $13.4 \%$.The prevalence of anxiety disorder was $6.5 \%$ and depressive disorder was $2.6 \%$ [18]. Sandal et.al (2017) study among students of grades 9 to 12 attending public schools in India showed that $65.53 \%$ had depression (in mild-extremely severe forms), 80.85\% suffered from anxiety (in mild-extremely severe forms), and $4.02 \%$ had stress (mild-extremely severe) [19]. Noteworthy, few studies have been conducted in this field and population in Iran. However, we wish to note that such problems are high in Iran. A meta-analysis partly evidences this by Sajjadi et al. (2013). Based on Sajjadi's study, the prevalence of depression among Iranian adolescents was 13.5 to $43.5 \%$. This was, however, revealed using different tools. One of the most important factors that has been implicated among adolescents experiencing depression is female gender and in spite of the importance of depression in adolescence, many other areas deserve attention [20].

Since adolescents with unsuitable mental health conditions are exposed to social exclusion, educational problems, and physical illnesses [4], paying attention to the mental health of this group is a priority for health promotion programs in the country. Given the sensitivity of this group, and since no extensive information was found on this subject and population in Iran, the present study has been conducted to measure satisfaction with life, depression, anxiety, and stress as the dimensions of mental health in a representative sample of adolescent girls in Tehran. Evidence from this study can be a basis for estimating the extent of adolescents' mental health in the country.

\section{Methodology}

This was a cross-sectional descriptive-analytical study conducted in February 2018 till March 2018 in Tehran, capital of Iran. The study population was adolescent girls in the last grade of high school. The inclusion criteria included: being female, being in the final grade of high school, residing in Tehran. The exclusion criterion had a physical disability.

The sample size was estimated for the Infinite population by using the following formula:

$n=\mathrm{Z} \alpha / 22{ }^{*} \mathrm{p} *(1-\mathrm{p}) / \mathrm{d} 2$ where, $\mathrm{Z} \alpha / 2$ is $1.96, \mathrm{~d}$ or the margin of error is 0.05 , and $p$ is a prevalence of depression which is $30 \%$ on the Montazeri et al. study [21],(as well cluster sampling effect of 1.5 was considered. Then by adding Five percent for non-responses and incomplete questionnaires, 508 questionnaires were distributed. The participants were selected using a multi-stage sampling method. Nineteen educational districts of Tehran were first placed in 4 clusters (such that the first cluster included districts; $15,16,17,18,19$; second cluster were districts; $9,10,11,12,13,14$; the third cluster included 
districts; $6,7,8,5,2$; and the fourth cluster were districts; $1,3,4)$. Then, one district was selected from each cluster randomly (in total, four districts were selected from 4 clusters). The four selected districts were districts number $1,5,10$, and 15 . Then, a public school and a non-public school were selected from each of the four selected districts. In the last step, simple random sampling was used to select students from the school. Since all subjects were under 18 years old, after arrangement with the principals of schools, consent forms were given to the student to be signed by their parents. Parents who consented that their children should participate in the research signed the form and returned it. The goals and general information about the study were explained to the students, it was voluntary to participate, and anonymity of data was maintained at all times.

Demographic information like age, father's job, and mother's job were asked. Alongside, two data gathering tools were used in this study. Satisfaction with life scale (SWLS) was used to measure satisfaction with life. The tool has five items scored on a 7-point Likert scale from strongly agree to strongly disagree. The range of scores was 5-35, and the higher scores showed higher satisfaction. In this classification, those who obtained 31 to 35 were extremely satisfied, 26 to 30 satisfied, 21 to 25 slightly satisfied, 20 neutral, 15 to 19 slightly dissatisfied, 10-14 dissatisfied, and 5-9 extremely dissatisfied. Considering that Cronbach alpha and Inter-class Correlation Coefficient (ICC) are common metrics for reliability, Bayani et al. (2007) obtained the reliability of satisfaction with life scale among law students using Cronbach alpha and ICC of 0.83 and 0.69 , respectively [22]. The Cronbach alpha in this study on the adolescent girls of Tehran was 0.90 , and Inter-class ICC was 0.82 .

Depression, anxiety, and stress were measured using the Depression, Anxiety, Stress Scale-21 (DASS-21) questionnaire. The Depression, Anxiety and Stress Scale - 21 Items (DASS-21) is a set of three self-report scales designed to measure the emotional states of depression, anxiety, and stress. The tool has 21 items scored on a 4-point Likert scale (that is, never to almost always). Seven questions (questions 3, 5, 10,13, 16, 17, 21) of this scale are related to depression, seven questions $[2,4,7$, $9,10,15,19]$ assess anxiety and seven questions $(1,6,8$, $11,12,14,18)$ assess stress. On the depression subscale, the scores were classified as follows: 0-9 normal condition, 10-13 mild depression, 14-20 moderate depression, $21-27$ severe depression, and above 28 as extremely severe depression. The scores on the anxiety subscale were: 0-7 normal condition, 8-9 mild anxiety, 10-14 moderate anxiety, 15-19 severe anxiety, and above 20 was extremely severe anxiety. On the stress subscale, the scores were: 0-14 normal condition, 15-18 mild stress, 19 to 25 moderate stress, $26-3$ severe stress, and above 33 extremely severe stress. In this study, the Persian version of the DASS-21 questionnaire, which has been translated and validated into Persian by Sahebi et al. (2005) was used [23]. Najafi-Kalyani et al. (2010), in their study among associate, bachelor, and Ph.D. students, calculated the validity of this questionnaire by using Cronbach alpha for stress, anxiety, and depression was 0.80, 0.86, and 0.83 , respectively [24]. The Cronbach alpha of the whole DASS-21 questionnaire in the present study was 0.87 , and ICC was 0.77 . Also, the Cronbach alpha of the DASS-21 questionnaire subscales of depression, anxiety, and stress in the present study was $0.83,0.78$, and 0.80 , respectively; the ICC for subscales of depression, anxiety, and stress was $0.85,0.77,0.85$, respectively.

Frequency and percentage were used to describe categorical variables, and in the case of continuous variables, mean and standard deviation were used. The Spearman's test was used for assessing bivariate correlation. Multiple regression models were performed to determine factors related to satisfaction with life using stepwise methods. Considering the design effect in cluster sampling, all analysis was performed in a survey using Stata 13 (StataCorp. 2013. Stata Statistical Software: Release 13. College Station, TX: StataCorp LP). The significant level was considered of $P<0.05$.

\section{Results}

In this study, from 508 distributed questionnaires, data from 491 questionnaires were analyzed, yielding a response rate of $96.7 \%$. The mean age of adolescents was $17.23 \pm 0.77$, with a range of $13-20$. Most fathers were employed (80.8\%), and only $2.9 \%$ were unemployed. The rest were retired or died. The majority of mothers were housekeepers $(77.7 \%)$, and $20.8 \%$ were employed. The mean and standard deviation of depression, anxiety, and stress subscales and their frequency distribution based on severity are shown in Table 1. Accordingly, More than half of the students showed some degree of depression, anxiety, and stress. The status of satisfaction with life, based on cut point, its mean scores, and the standard deviation, is presented in Table 2. In total, a notable percent of adolescents experienced severe and extremely severe forms of depression (16.8\%), anxiety (28.3\%), and stress symptoms (19.1\%). About $30 \%$ of them had some degree of dissatisfaction with life.

The result of the Spearman's test showed that there is a correlation between satisfaction with life and anxiety $(r=-0.364, p<0.001)$, depression $(r=0.588, p<0.001)$, stress $(r=-0.401, p<0.001)$ and age $(r=-0.155$, $p<0.001)$.

A regression model was fitted for the four variables (depression, anxiety, stress, and age). Since anxiety 
Table 1 Frequency distribution of depression, anxiety and stress in adolescent girls in Tehran $(n=491)$

\begin{tabular}{|c|c|c|c|c|c|c|c|c|c|c|}
\hline \multirow[t]{2}{*}{ No. } & \multirow[t]{2}{*}{ Severity } & \multicolumn{3}{|l|}{ Depression } & \multicolumn{2}{|l|}{ Anxiety } & \multirow[b]{2}{*}{$95 \% \mathrm{Cl}$} & \multicolumn{2}{|l|}{ Stress } & \multirow[b]{2}{*}{$95 \% \mathrm{Cl}$} \\
\hline & & Number & Percent & $95 \% \mathrm{Cl}$ & Number & Percent & & Number & Percent & \\
\hline 1 & Normal & 232 & 48.34 & $42.83,53.90$ & 198 & 41.72 & $34.14,49.71$ & 232 & 47.68 & $42.92,52.48$ \\
\hline 2 & Mild & 74 & 15.01 & $11.81,18.90$ & 37 & 8.17 & $6.07,10.91$ & 87 & 18.98 & $17.37,20.71$ \\
\hline 3 & Moderate & 95 & 20.53 & $17.05,24.51$ & 105 & 22.52 & $17.96,27.83$ & 72 & 15.45 & $11.41,20.60$ \\
\hline 4 & Severe & 35 & 7.28 & $4.34,11.99$ & 51 & 10.60 & $8.24,13.53$ & 57 & 11.92 & $8.79,15.97$ \\
\hline \multirow[t]{2}{*}{5} & Extremely Severe & 43 & 8.83 & $6.11,12.60$ & 80 & 17.00 & $13.57,21.08$ & 27 & 5.96 & $3.52,9.91$ \\
\hline & Mean (SD) & $11.56(0.35)$ & & $10.74,12.39$ & $10.73(0.57)$ & & $9.38,12.08$ & $16.11(0.51)$ & & $14.89,17.33$ \\
\hline
\end{tabular}

Table 2 Frequency distribution of satisfaction with life in adolescents girls of Tehran $(n=491)$

\begin{tabular}{|c|c|c|c|c|c|c|c|}
\hline Satisfaction with life & $\begin{array}{l}\text { Extremely } \\
\text { satisfied }\end{array}$ & Satisfied & slightly satisfied & neutral & $\begin{array}{l}\text { slightly } \\
\text { dissatisfied }\end{array}$ & Dissatisfied & $\begin{array}{l}\text { Extremely } \\
\text { dissatisfied }\end{array}$ \\
\hline Number & 79 & 137 & 116 & 13 & 63 & 51 & 27 \\
\hline Percent & 16.78 & 27.59 & 23.84 & 2.87 & 12.36 & 11.26 & 5.30 \\
\hline \multirow[t]{2}{*}{$95 \% \mathrm{Cl}$} & 11.67 & 22.64 & 16.84 & 1.90 & 9.96 & 8.54 & 3.72 \\
\hline & 23.52 & 33.17 & 32.61 & 4.31 & 15.25 & 14.70 & 7.50 \\
\hline Mean (SD) & \multicolumn{7}{|c|}{$23.12(0.50), 95 \%$ Cl: $21.94,24.30$} \\
\hline
\end{tabular}

Table 3 the result of multiple regression analysis between depression and age as predictor variables and satisfaction with life as a criterion

\begin{tabular}{llll}
\hline variables & Beta & Standard deviation & $\boldsymbol{p}$-value \\
\hline Depression & -0.432 & 0.023 & $<0.001$ \\
Age & -1.62 & 0.239 & $<0.001$ \\
\hline
\end{tabular}

and stress were not significant, by eliminating them, the regression coefficient and $p$-value were changed (Table 3 ). The regression analysis results indicated that depression and age have a significant association with satisfaction with life after adjustment for anxiety and stress.

\section{Discussion}

In this study, based on the DASS-21 questionnaire, more than half of adolescents showed a notable degree of depression, anxiety, and stress. Specifically, our study identified that a considerable proportion of adolescents experienced severe and extremely severe forms of depression (16.8\%), anxiety (28.3\%), and stress (19.1\%). Elsewhere, such remarkably high proportions of the mental problems under consideration in our study have been reported. For instance the results of Kordi et al. (2015) study among the female high-school students of Mashhad showed that $21.7 \%$ experienced severe and extremely severe self-reported depressive symptoms,
24.3\% had severe and extremely severe self-reported anxiety symptoms and $21.8 \%$ had severe and extremely severe self-reported stress symptoms [25]. The systematic review by Montazeri et al. (2013) in Iran showed that the prevalence of depression among the different populations of Iran was reported as 5.69-73\%. The highest amount was related to female high-school students in Firozkogh city [21]. According to Sahoo and Khess's (2010) study, the depression, anxiety, and stress symptoms were $18.5,24.4$, and $20 \%$, respectively, in 17-22 years old students in India [26]. Generally, the above-noted findings from previous studies [18-20] are consistent with the present study results. The systematic review study of Polanczyk et al. (2015) estimated that about 241 million youths worldwide suffer from some form of mental disorder [18]. Depressive disorders and anxiety disorders are highly prevalent in the population. At a global level, over 300 million people are estimated to suffer from depression, equivalent to $4.4 \%$ of the world's population. The number of persons with common mental disorders globally is going up, particularly in lower-income countries, because the population is growing and more people are living to the age when depression and anxiety most commonly occur [27]. Regarding the depression, anxiety, and stress in female students in the present study and since the continuance of mental health problems have detrimental effects on academic achievement as well as on the potential that adolescent girls might have. We 
recommend that interventional studies in this context could be beneficial to avert such notable levels of mental health problems revealed in this study.

This study indicated that about $30 \%$ of adolescents were dissatisfied with life dissatisfaction. The results of Okwrji's (2016) study using SWLS showed that among adolescents aged between 16 and 19 years, 32.3\% were dissatisfied with life [28].. This is consistent with the findings of this study. In a 4-year longitudinal study in Hong Kong, Shek showed that the mean satisfaction with life, based on SWLS, reduced from $19.38 \pm 5.37$ to $18.54 \pm 5.27$. Generally, based on this tool, satisfaction with life among adolescents was lower than the neutral level. This means they were slightly dissatisfied with life [29]. This is partly attributed to the fact that during adolescence, the sensitivities increase, and the goals renew. Thus, satisfaction with life in this period is an important psychological variable. Through developing cognitive capabilities, the adolescent can evaluate and predict the primary needs with higher precision [30]. Based on the findings of this study, satisfaction with life in a considerable percent of adolescents was below moderate.

This study showed that satisfaction with life is correlated with depression, anxiety, and stress. According to the regression model, depression and age are correlated variables of satisfaction with life. It seems that performing interventions to moderate and change life dissatisfaction is necessary. We hope that the results from our study that highlighted the correlation between various mental problems and satisfaction with life could guide such interventions. Similarly, the previous studies showed that lower satisfaction with life among adolescents and adults predicts higher depression levels [28, 31]. Shi (2015), using SWLS among 2925 students in China, showed that stress has a negative correlation with satisfaction with life $(\mathrm{r}=-035 ; p<0.01)$ [32]. Guney et al. (2010) study in Turkey showed that in 364 students in the age range of 19 to 25 years old, the satisfaction with life, that was measured with SWLS, has a negative correlation with anxiety which is measured by Beck Anxiety Inventory $(r=-0.26$, $\mathrm{p}<0.01)$ [2].

The results of Moksens \& Espnes were consistent with the results of this study regarding the relationship of age and satisfaction with life among male Norwegian adolescents [7]. Contrary, the Al-Attiyh study showed that age has no significant association with satisfaction with life [33]. Aging comes with biological and mental changes that can affect people's goals and wishes in life and their feelings about satisfaction with life. Aging is also associated with the changes in the role of individuals and increasing responsibilities. These changes may increase or decrease the level of satisfaction with life, based on an individual's perception of her/his conditions.
One of the strengths of this research was that it used a representative sample size. On the other hand, this study is not without limitations. The measures used for screening are not considered diagnostic tools but rather identify those who may need further evaluation and possible intervention. A specialist should make a diagnosis with specialized clinical examinations. Also, the study only considered adolescent girls in their final grade. Owing to the differences in life experiences of girls and boys, these findings could only be generalizable in the context of adolescent girls.

\section{Conclusion}

The results of this study indicated that a significant proportion of adolescents experience some form of depression, anxiety, and stress and experience suboptimal satisfaction with life. Findings also suggest that depression and age have an impact on life satisfaction. Therefore, appropriate screening programs and interventions are essential to identify and treat depression in adolescents.

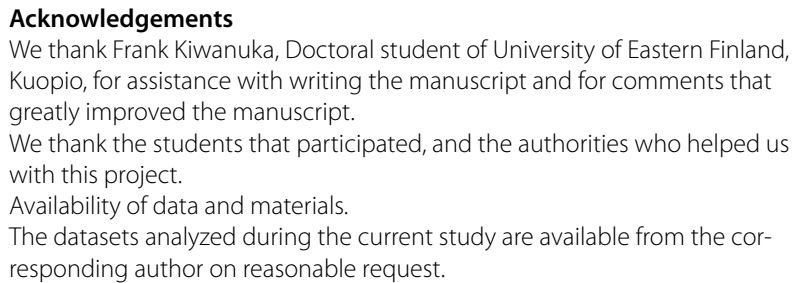

\section{Authors' contributions}

Sara-Sadat Hoseini-Esfidarjani and Reza Negarandeh conceptualized the research design and study objectives; Sara-Sadat Hoseini-Esfidarjani coordinated data collection and entry; Kiarash Tanha contributed to data analysis and interpretation; Reza Negarandeh acted as the lead author of the manuscript and Sara-Sadat Hoseini-Esfidarjani provided critical review of the manuscript. All authors read and approved the final manuscript. Conception \& design: Sara-Sadat Hoseini-Esfidarjani, Reza Negarandeh. Data acquisition: Sara-Sadat Hoseini-Esfidarjani. Data Analysis: KiarashTanha. Drafting article and revising: Sara-Sadat Hoseini-Esfidarjani.

\section{Funding}

This research has been supported by the Tehran University of Medical Sciences \& Health Services grant (No: 34738).

\section{Declarations}

\section{Ethics approval and consent to participate}

The study was evaluated and approved by the School of Nursing and Midwifery \& Rehabilitation-Tehran University of Medical Sciences (Ethical code: IR.TUMS.FNM.REC.1369.2698). Written informed consent was obtained from all individual participants included in the study.

We confirm that all methods were performed in accordance with the relevant guidelines and regulations

\section{Consent for publication}

Not applicable.

\section{Competing interests}

The author(s) declare(s) that they have no competing interests. 


\begin{abstract}
Author details
${ }^{1}$ Nursing and Midwifery Care Research Center, Tehran University of Medical Sciences, Nosrat St., Tehran 1419733171, Iran. ${ }^{2}$ Department of Biostatistics, School of Public Health, Iran University of Medical Sciences, ShahidHemmatHighway, Tehran 1449614535, Iran. ${ }^{3}$ Nursing and Midwifery Care Research Center, Tehran University of Medical Sciences, Nosrat St., Tohid Sq., Tehran 1419733171, Iran.
\end{abstract}

Received: 18 October 2020 Accepted: 4 February 2022 Published online: 11 February 2022

\section{References}

1. World Health Organization (WHO). Mental health: a state of well-being. Updated August 2014]. Retrieved from https://www.who.int/features/factf iles/mental_health/en/.

2. Guney S, Kalafat T, Boysan M. Dimensions of mental health: life satisfaction, anxiety and depression: a preventive mental health study in Ankara University students population. Procedia Soc Behav Sci. 2010;2(2):1210-3 Retrieved from https://www.sciencedirect.com/science/article/pii/S1877 042810002144.

3. Jaworska N, MacQueen G. Adolescence as a unique developmental period. J Psychiatry Neurosci. 2015;40(5):-291, 3. https://doi.org/10.1503/jpn. 150268.

4. World Health Organization (WHO). Adolescent mental health. 18 September 2018]. Retrieved from https://www.who.int/news-room/fact-sheets/ detail/adolescent-mental-health

5. World Health Organization (WHO). Maternal, newborn, child and adolescent health.]. Retrieved from https://www.who.int/maternal_child_adolescent/ topics/adolescence/mental health/en/.

6. Schütz E, Sailer U, AI Nima A, Rosenberg P, Arntén AC, Archer T, et al. The affective profiles in the USA: happiness, depression, life satisfaction, and happiness-increasing strategies. PeerJ. 2013;1:e156. https://doi.org/10.7717/ peerj.156.

7. Moksnes UK, Espnes GA. Self-esteem and life satisfaction in adolescentsgender and age as potential moderators. Qual Life Res. 2013;22(10):2921-8. https://doi.org/10.1007/s11136-013-0427-4

8. Al Khatib SA. Satisfaction with life, self-esteem, gender and marital status as predictors of depressive symptoms among United Arab Emirates college students. Int J Psychol Counsell. 2013;5(3):59-61 Retrieved from https:// academicjournals.org/journal/IJPC/article-abstract/5318A2138659.

9. Mahoney JW, Quested E, Thøgersen-Ntoumani C, Ntoumanis N, Gucciardi DF. Validating a measure of life satisfaction in older adolescents and testing invariance across time and gender. Pers Individ Differ. 2016;99:217-24. https://doi.org/10.1016/j.paid.2016.05.015.

10. Srivastava A. Relationship between life satisfaction and depression among working and non-working married women. Int J Educ Psychol Res. 2016;5(3):1-7 Retrieved from https://paperzz.com/doc/8278111/relationsh ip-between-life-satisfaction-and-depression-among.

11. Pickett W, Berg RL, Kaprelian J, Marlenga B. A contemporary profile of the mental health of girls from farm and non-farm environments. J Agromedicine. 2020;25(1):96-105. https://doi.org/10.1080/1059924X.2019.1623142.

12. Saraf G, Chandra PS, Desai G, Rao GN. What adolescent girls know about mental health: findings from a mental health literacy survey from an urban slum setting in India. Indian J Psychol Med. 2018;40(5):433-9. https://doi. org/10.4103/IJPSYM.IJPSYM_108_18.

13. Rao S, Ramesh N. Depression, anxiety and stress levels in industrial workers: a pilot study in Bangalore, India. Ind Psychiatry J. 2015;24(1):23-8. https:// doi.org/10.4103/0972-6748.160927.

14. Torres F. What is depression? : American Psychiatric Association 2020. Retrieved from https://www.psychiatry.org/patients-families/depression/ what-is-depression.

15. Malik M, Khanna P, Rohilla R, Mehta B, Goyal A. Prevalence of depression among school going adolescents in an urban area of Haryana, India. Int J Commun Med Public Health. 2017;2(4):624-6. https://doi.org/10.18203/ 2394-6040.ijcmph20151059.

16. Watode BK, Kishore J, Kohli C. Prevalence of stress among school adolescents in Delhi. Indian J Youth Adolesc Health. 2015;2(4):5-9 Retrieved from https:// scholar.google.com/scholar?hl=en\&as_sdt=0\%2C5\&q=\%22Prevalence+ of+Stress+among+school+Adolescents+in+Delhi\%22\&btnG=.
17. Latiff LA, Sidik SM, Ibrahim N, Othman N, Bakar AS. Prevalence of anxiety and its association with socio-demographic factors among secondary school students in Pasir Gudang district, Johor. Int J Public Health Clin Sci. 2015;2(6):104-12 Retrieved from http://www.publichealthmy.org/ejournal/ ojs2/index.php/ijphcs/article/view/257.

18. Polanczyk GV, Salum GA, Sugaya LS, Caye A, Rohde LA. Annual research review: a meta-analysis of the worldwide prevalence of mental disorders in children and adolescents. J Child Psychol Psychiatry. 2015;56(3):345-65. https://doi.org/10.1111/jcpp.12381.

19. Sandal RK, Goel NK, Sharma MK, Bakshi RK, Singh N, Kumar D. Prevalence of depression, anxiety and stress among school going adolescent in Chandigarh. J Family Med Prim Care. 2017;6(2):405-10. https://doi.org/10.4103/ 2249-4863.219988.

20. Sajjadi H, Kamal SH, Rafiey H, Vameghi M, Forouzan AS, Rezaei M. A systematic review of the prevalence and risk factors of depression among iranian adolescents. Glob J Health Sci. 2013;5(3):16-27. https://doi.org/10.5539/gjhs. v5n3p16.

21. Montazeri A, Mousavi SJ, Omidvari S, Tavousi M, Hashemi A, Rostami T. Depression in Iran: a systematic review of the literature (2000-2010). J Iranian Institute Health Sci. 2013;12(6):567-94 Retrieved from https://www.sid.ir/En/ Journal/NiewPaper.aspx? ID=333346.

22. Bayani AA, Koocheky AM, Goodarzi $H$. The reliability and validity of the satisfaction with life scale. J Psychologists. 2007;3(11):259-65 Retrieved from https://www.sid.ir/En/Journal/ViewPaper.aspx? ID=101773.

23. Sahebi A, Asghari MJ, Salari RS. Validation of depression anxiety and stress scale (DASS-21) for an Iranian population. 2005. Retrieved from http://jip. azad.ac.ir/article 512443 en.html.

24. Najafi Kalyani M, Pourjam E, Jamshidi N, Karimi SH, Najafi KV. Survey of stress, anxiety, depression and self-concept of students of Fasa University of Medical Sciences, 2010. J Fasa Univ Med Sci. 2013;3(3):235-40 Retrieved from http://journal.fums.ac.ir/article-1-361-en.html.

25. Kordi M, Mohamadirizi S, Shakeri MT, ModarresGharavi M, Salehi FJ. The relationship between depression, anxiety, stress and health behaviors in high school girl students in Mashhad in year 2011-2012. Tolooebehdasht. 2015;13(5):56-67 Retrieved from http://tbj.ssu.ac.ir/browse.php?a_id= $1288 \&$ slc_lang $=$ en\&sid $=1$ \&printcase $=1 \& \mathrm{hbnr}=1 \& \mathrm{hmb}=1$.

26. Sahoo S, Khess CR. Prevalence of depression, anxiety, and stress among young male adults in India: a dimensional and categorical diagnoses-based study. J Nerv Ment Dis. 2010;198(12):901-4. https://doi.org/10.1097/NMD. ob013e3181fe75dc

27. World Health Organization (WHO). Depression and other common mental disorders: global health estimates, vol. 24; 2017. Retrieved from https://apps. who.int/iris/handle/10665/254610

28. Okwaraji FE, Aguwa EN, Shiweobi-Eze C. Life satisfaction, self-esteem and depression in a sample of Nigerian adolescents. Int Neuropsychiatr Dis J. 2016;5(3):1-8. https://doi.org/10.31254/jmr.2017.3207.

29. Shek DT, Li X. Perceived school performance, life satisfaction, and hopelessness: a 4-year longitudinal study of adolescents in Hong Kong. Soc Indic Res. 2016;126(2):921-34. https://doi.org/10.1007/s11205-015-0904-y.

30. Bradley R, Corwyn R. Life satisfaction among european american, african american, chinese american, mexican american, and dominican american adolescents. Int J Behav Dev. 2004;28(5):385-400. https://doi.org/10.1080/ 01650250444000072.

31. Zawawi JA, Hamaideh SH. Depressive symptoms and their correlates with locus of control and satisfaction with life among Jordanian college students. Eur J Psychol. 2009;5(4):71-103 Retrieved from https://ejop.psychopen.eu/ article/view/241.

32. Shi $M$, Wang $X$, Bian $Y$, Wang $L$. The mediating role of resilience in the relationship between stress and life satisfaction among Chinese medical students: a cross-sectional study. BMC Med Educ. 2015;15(1):16. https://doi. org/10.1186/s12909-015-0297-2.

33. Al-Attiyah A, Nasser R. Gender and age differences in life satisfaction within a sex-segregated society: sampling youth in Qatar. Int J Adolesc Youth. 2016;21(1):84-95 Retrieved from https://www.tandfonline.com/doi/full/10. 1080/02673843.2013.808158.

\section{Publisher's Note}

Springer Nature remains neutral with regard to jurisdictional claims in published maps and institutional affiliations. 